\begin{tabular}{|c|c|}
\hline Title & $\begin{array}{l}\text { Photoelectrochemical Generation of Hydrogen at Electrochemically Deposited p-CdTe Films: Effect of Heat- } \\
\text { Treatment, Surface Modification by Platinum and Surface Oxide Layer on Conversion Efficiency }\end{array}$ \\
\hline Author(s) & Takahashi, Makoto; U osaki, Kohei; Kita, Hideaki \\
\hline Citation & $\begin{array}{l}\text { Journal of The Electrochemical Society, 133(2), 266-271 } \\
\text { https://doi.org/10.1149/1.2108560 }\end{array}$ \\
\hline Issue Date & 1986 \\
\hline Doc URL & http:/hdl.handle.net/2115/50253 \\
\hline Rights & $\begin{array}{l}\text { (C) The Electrochemical Society, Inc. 1986. All rights reserved. Except as provided under U.S. copyright law, this work } \\
\text { may not be reproduced, resold, distributed, or modified without the express permission of The Electrochemical Society } \\
\text { (ECS). The archival version of this work was published in J. Electrochem. Soc. } 1986 \text { volume 133, issue 2, 266-271. }\end{array}$ \\
\hline Type & article \\
\hline File Information & JES133-2_266-271.pdf \\
\hline
\end{tabular}

Instructions for use 


\section{Photoelectrochemical Generation of Hydrogen at Electrochemically Deposited p? -?CdTe Films: Effect of Heat -Treatment, Surface Modification by Platinum and Surface Oxide Layer on Conversion Efficiency}

Makoto Takahashi, Kohei Uosaki and Hideaki Kita

J. Electrochem. Soc. 1986, Volume 133, Issue 2, Pages 266-271. doi: $10.1149 / 1.2108560$

Email alerting Receive free email alerts when new articles cite this article - sign up service in the box at the top right corner of the article or click here

To subscribe to Journal of The Electrochemical Society go to: http://jes.ecsdl.org/subscriptions

(C) 1986 ECS - The Electrochemical Society 


\title{
Photoelectrochemical Generation of Hydrogen at Electrochemically Deposited p-CdTe Films: Effect of Heat-Treatment, Surface Modification by Platinum and Surface Oxide Layer on Conversion Efficiency
}

\author{
Makoto Takahashi, Kohei Uosaki, ${ }^{*}$ and Hideaki Kito \\ Department of Chemistry, Faculty of Science, Hokkaido University, Sapporo 060, Japan
}

\section{ABSTRACT}

The effects of heat-treatment, Pt modification of the surface and surface oxide layer on the efficiency for the photoelectrochemical generation of hydrogen were investigated at $\mathrm{p}$-CdTe films deposited electrochemically at $-0.35 \mathrm{~V}(v s$. $\mathrm{Ag} / \mathrm{AgCl}$ ) from an aqueous sulfuric acid solution of $\mathrm{pH}=1.4$ containing $1 \mathrm{M} \mathrm{CdSO}_{4}$ and $1 \mathrm{mM} \mathrm{TeO}_{2}$. By heat-treatment in a He atmosphere, the crystalline diameter increased and, thus, the number of grain boundaries at which effective electron-hole recombination takes place decreased. Free metallic Te existing near the surface, which acts as a recombination center, was removed by the treatment at the temperatures above $350^{\circ} \mathrm{C}$. The cathodic photocurrent was increased by the heat-treatment due to these two effects. The cathodic photocurrent was decreased and even the anodic photocurrent was observed at the films treated at too high a temperature and for too long a time. The films were converted to $\mathrm{n}$-type by these treatments because of the removal of the lattice Te from CdTe crystal. Pt modification, either vacuum deposition or codeposition, improved the efficiency, but the photocurrent is small, suggesting that the major reason for the low efficiency is still the bulk recombination. The oxide layer was easily formed on the CdTe films by exposure to air but dissolved by contacting with solution and had no effect on the photoelectrochemical properties of the film.

Recently strong attention has been paid to photoelectrolysis of water by using semiconductor electrodes as one of the useful means to convert solar energy into chemical energy, hydrogen (1). To make this process practical, it is essential to find an economical method for the production of polycrystalline semiconductors which have appropriate photoelectrochemical characteristics (2).

Cadmium telluride ( $\mathrm{CdTe}$ ) has the following attractive properties for solar energy conversion devices. The bandgap energy is $1.45 \mathrm{eV}$ (3) from which one expects a high solar energy conversion efficiency (4). The direct optical transition (5) results in a large absorption coefficient which makes the use of thin film solar cells possible. Both p- and n-type forms can be prepared (6). Thus, the application of Cd Te to solid-state solar cells (7) and photoelectrochemical cells (8) have been studied very extensively. One of us found p-CdTe is a stable cathode material for the photoelectrochemical generation of hydrogen (9).

The electrochemical deposition has been studied extensively as a useful method for preparing large area, polycrystalline Cd-chalcogenides (10). The photoelectrochemical properties of electrochemically deposited Cdchalcogenide thin films have also been reported by many research groups but most of the reports are on n-type materials (11).

We have recently investigated the electrochemical deposition of CdTe thin films from the solution containing $\mathrm{CdSO}_{4}$ and $\mathrm{TeO}_{2}$ and reported the effect of preparation conditions, e.g., deposition potential, on the composition and optical and electronic properties of the deposited films (12-14). We also studied the photoelectrochemical generation of hydrogen at the electrochemically deposited $\mathrm{p}$-CdTe films $(12,14)$. The conversion efficiency at the as-grown films was poor compared with that at single crystal electrodes. The following are considered to be the reasons for the low efficiency: (i) There are many grain boundaries in the films at which effective recombination takes place. (ii) Free excess metallic Te which acts as recombination center exists near the surface. (iii) The hydrogen evolution reaction rate at the semiconductor electrode is low.

In this paper, to overcome the above difficulties and to improve the efficiency, the effects of heat-treatment and surface modification by platinum on the photoelectrochemical generation of hydrogen at electrochemically de-

*Electrochemical Society Active Member. posited p-CdTe films are investigated. The effect of surface oxide layer which was reported to affect the efficiency at $\mathrm{p}$-InP (15) is also examined.

\section{Experimental}

p-CdTe thin films were deposited on Ti sheet, which was degreased by a chloroform, then by an ethanol vapor, etched by $10 \%$ HF solution, and washed by deionized water before use from an aqueous sulfuric acid solution of $\mathrm{pH}=1.4$ containing $1 M \mathrm{CdSO}_{4}$ and $1 \mathrm{mM} \mathrm{TeO}(4)$. The deposition potential was usually $-0.35 \mathrm{~V}$ (vs. $\mathrm{Ag} / \mathrm{AgCl}$ ) and the deposition current was ca. $0.15 \mathrm{~mA} \cdot \mathrm{cm}^{-2}$. The thickness of as-grown CdTe film was usually $3 \mu \mathrm{m}$ and the deposition took ca. $15 \mathrm{~h}$. The reagent grade $\mathrm{H}_{2} \mathrm{SO}_{4}, \mathrm{CdSO}_{4}$ (purity $99.5 \%$ ), and $\mathrm{TeO}_{2}$ (purity $99 \%$ ) of Wako Pure Chemicals, Incorporated were used without further purification. Water was purified by a Milli Q water purification system (Millipore Corporation). A usual three-electrode cell was used both for the electrochemical deposition and for the photoelectrochemical measurements. A platinum sheet and a $\mathrm{Ag} / \mathrm{AgCl}$ electrode were used as a counter and a reference electrode, respectively. A potentiostat (Wenking Model 68 FRO.5 or Nikko Keisoku NPGS-301 s) was used to control the electrode potential. The deposition of films and the photoelectrochemical measurements were carried out at room temperature after the electrolyte solution was deaerated by passing a purified He gas through the solution for about $20 \mathrm{~min}$. The photoelectrochemical measurements were carried out in $1 M$ $\mathrm{NaOH}$. A 500W Xe lamp (Usio Denki Company Limited) with an IR absorbing filter (Toshiba IRA-20) was used as a light source. The intensity of the light at the electrode surface was ca. $17 \mathrm{~mW} \cdot \mathrm{cm}^{-2}$.

The heat-treatment of the films was carried out in a quartz tube under a $\mathrm{He}$ gas flow. The temperature was measured with a Chromel-Alumel thermocouple and controlled by using a thermocontroller (Model E560, Chino Work, Limited) within an accuracy of $\pm 5^{\circ} \mathrm{C}$. Temperature was raised to a preset value with a rate of ca. $100^{\circ} \mathrm{C} / \mathrm{h}$.

Two methods were employed to modify the electrode surface with $\mathrm{Pt}$. The first one was the codeposition of Pt. Just before the electrodeposition of CdTe was completed, $\mathrm{H}_{2} \mathrm{PtCl}_{6}$ solution was added to the electrolyte solution so that $\mathrm{Pt}$ concentration of the solution became $0.4 \mathrm{mM}$. The amount of $\mathrm{Pt}$ deposited was calculated from the difference between the charge passed when $\mathrm{Pt}$ was added and 


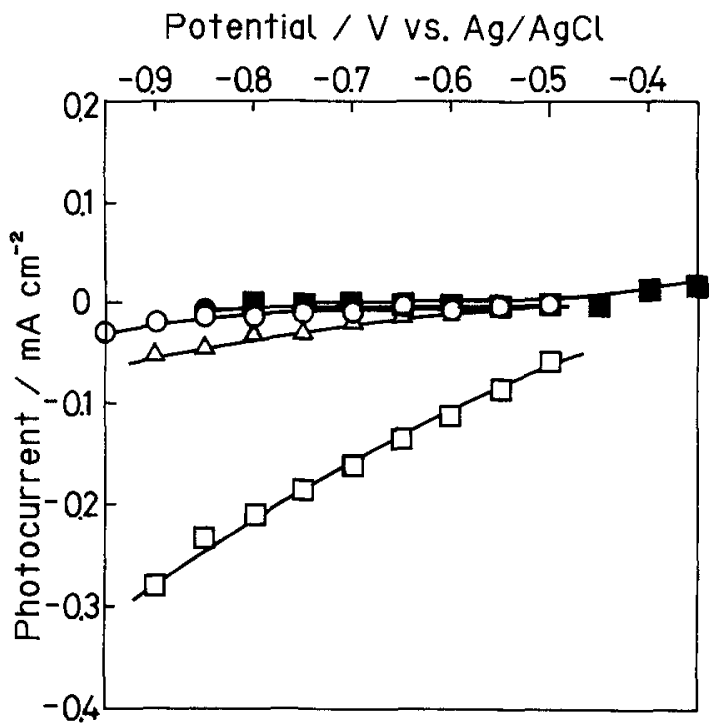

Fig. 1. Photocurrent-potential relations of p-CdTe films deposited on Ti sheet at $-0.35 \mathrm{~V}$ (vs. $\mathrm{Ag} / \mathrm{AgCl}$ ) from an aqueous sulfuric acid solution of $\mathrm{pH}=1.4$ containing $1 \mathrm{M} \mathrm{CdSO}_{4}$ and $1 \mathrm{mM} \mathrm{TeO}$. The measurements were carried out in $1 \mathrm{M} \mathrm{NoOH}$ with $500 \mathrm{~W} X$ lamp illumination. : Asgrown. Other films were onnealed in a $\mathrm{He}$ atmosphere for $4 \mathrm{~h}$ at $200^{\circ} \mathrm{C}$ $(O), 350^{\circ} \mathrm{C}(\square), 400^{\circ} \mathrm{C}(\triangle)$, and $500^{\circ} \mathrm{C}(\mathrm{C})$.

that without $\mathrm{Pt}$ addition. Heat-treatment was carried out as for the films without modification. In the other method, Pt was vacuum deposited on the films by using Ulvac, EBH-6. In this case, the thickness of Pt was measured by using an interference microscope (Mizojiri Optical Company Limited, Model 2).

The type of semiconductivity of the CdTe films were determined by measuring the potential difference between a hot and a cold contact. X-ray diffraction patterns and reflection spectra were obtained by using Toshiba $\mathrm{XC}-40$ x-ray diffractometer and a Beckman DK-2 reflectometer, respectively. X-ray photoelectron spectroscopy (XPS) measurements were carried out by using a V. G. Scientific, Limited, ESCA3.

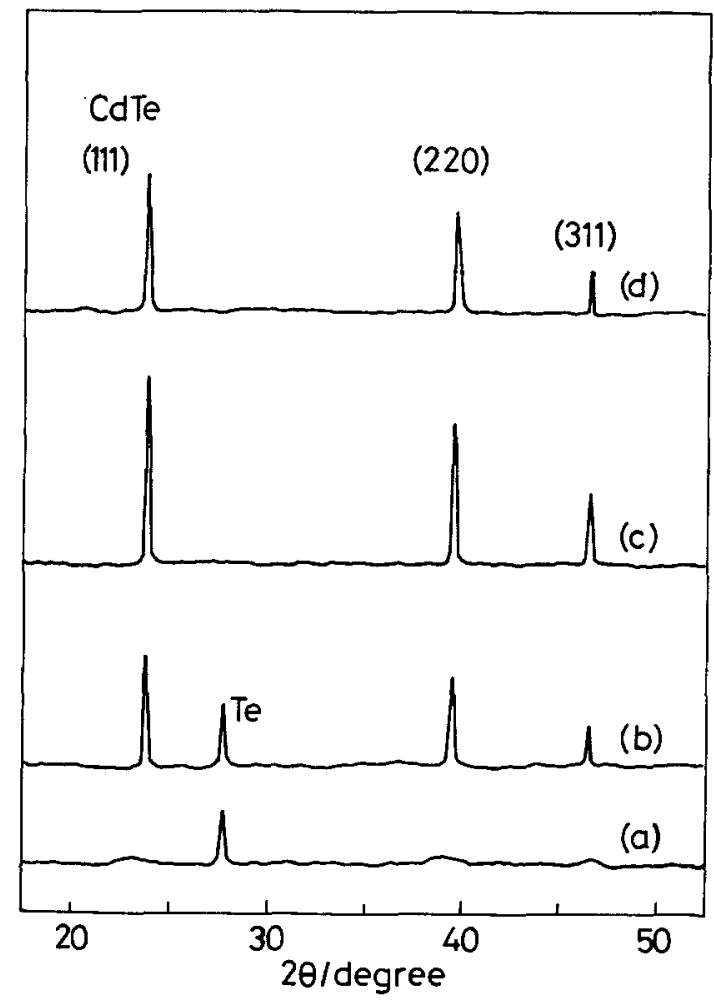

Fig. 2. X-ray diffraction patterns of the CdTe films used for the experiments presented in Fig. 1. (a) As grown, (b) annealed at $200^{\circ} \mathrm{C}$, (c) onnealed at $350^{\circ} \mathrm{C}$, and (d) annealed ot $500^{\circ} \mathrm{C}$.

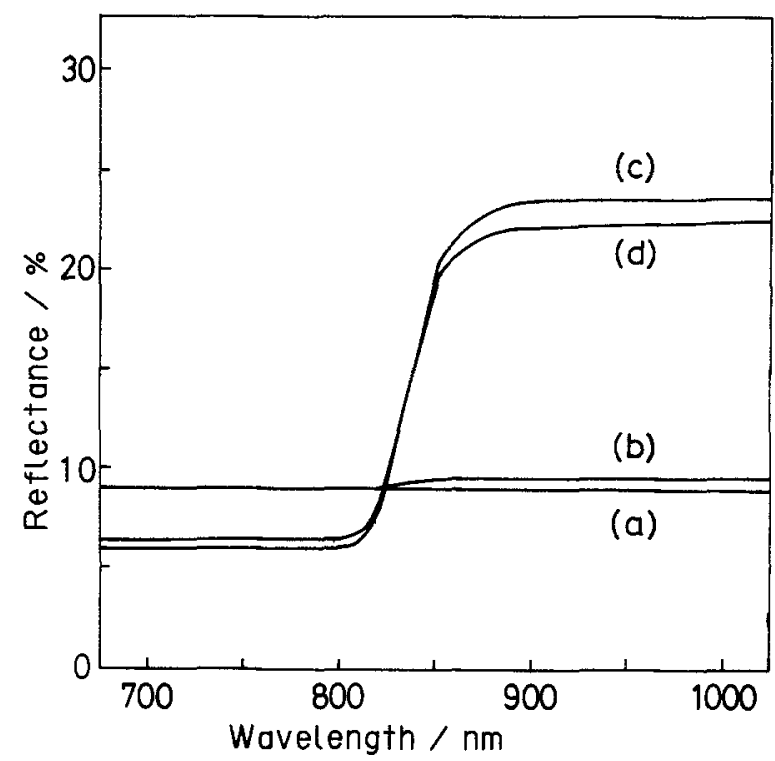

Fig. 3. Reflection spectra of the CdTe films used for the experiments presented in Fig. 1. (a) As grown, (b) annealed at $200^{\circ} \mathrm{C}$, (c) annealed at $350^{\circ} \mathrm{C}$, and (d) annealed at $500^{\circ} \mathrm{C}$.

\section{Results}

Effect of heat-treatment.-Figure 1 shows the photocurrent-potential relations of electrochemically deposited p-CdTe films annealed for $4 \mathrm{~h}$ at several temperatures. ${ }^{1}$ The cathodic photocurrent increased with the increase of annealing temperature up to $350^{\circ} \mathrm{C}$ and then decreased at higher temperatures as at $400^{\circ}$ and $500^{\circ} \mathrm{C}$. Even the anodic photocurrent was observed at the films treated at the temperatures above $400^{\circ} \mathrm{C}$.

The x-ray diffraction patterns of the annealed films shown in Fig. 2 demonstrate that the diffraction peak due to free metallic $\mathrm{Te}$ which existed in as-grown films remained at the films treated at $200^{\circ} \mathrm{C}$ but disappeared on annealing at higher temperatures. The intensity of diffraction peaks due to CdTe increased and the full width at half maximum (FWHM) of the peaks decreased by the

1 Each data point in most of the figures represents the average value of 2-4 independent experiments. The deviation of data was within the size of the symbols $(O, \square$, etc.) in the figures.

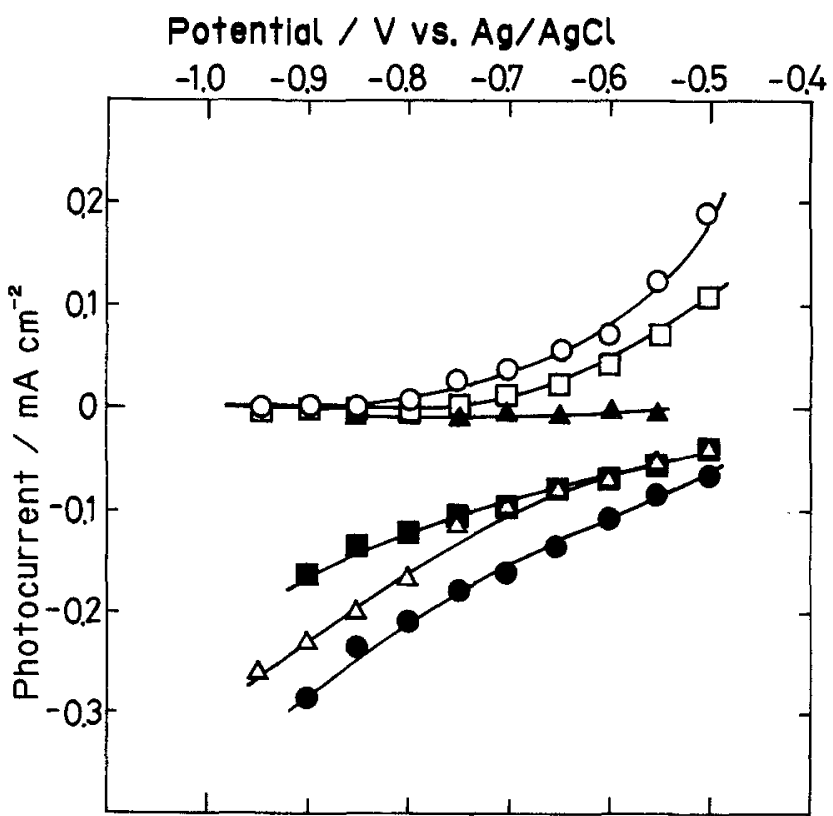

Fig. 4. Photocurrent-potential relations of p-CdTe films. Experimental conditions for the deposition and the photoelectrochemical measurements were the same as those in Fig. 1. A: As grown. Other films were annealed in o He atmosphere at $350^{\circ} \mathrm{C}$ for $2 \mathrm{~h}(\square), 4 \mathrm{~h}(\Theta), 6 \mathrm{~h}(\Delta), 7 \mathrm{~h}(\square)$ and $12 \mathrm{~h}(\mathrm{O})$. 


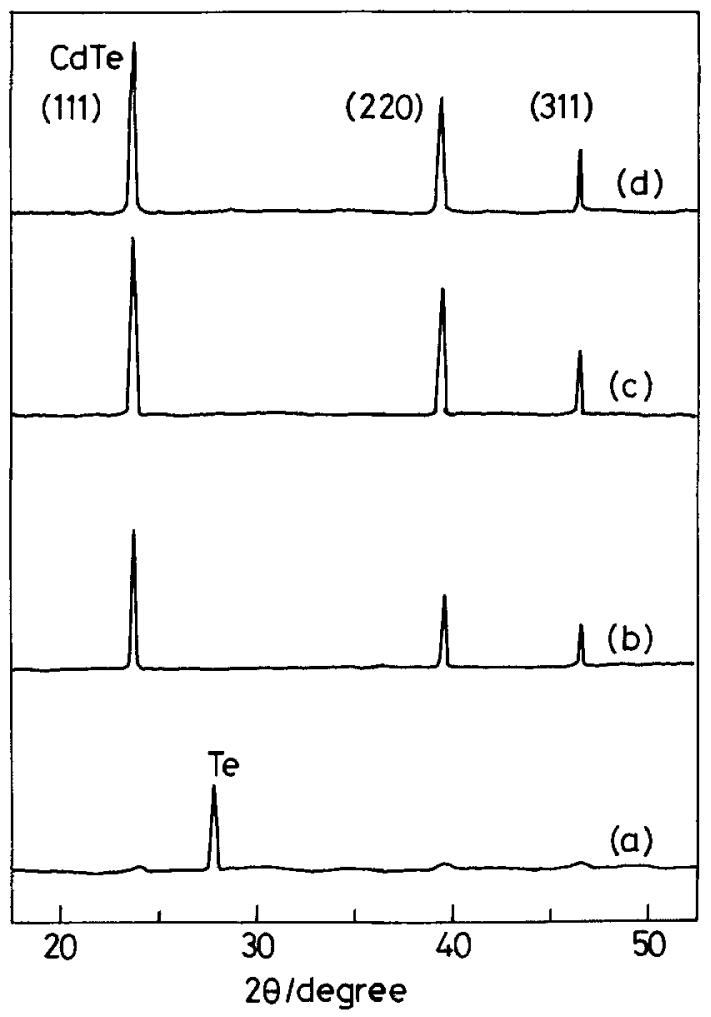

Fig. 5. X-ray diffraction patterns of the $\mathrm{CdTe}$ films used for the experiments presented in Fig. 4. (a) As grown, (b) annealed for $2 \mathrm{~h}$, (c) annealed for $4 \mathrm{~h}$, (d) annealed for $12 \mathrm{~h}$.

heat-treatment. The higher the temperature, the stronger the intensity of the peaks. The intensity, however, became weaker by the treatment at $500^{\circ} \mathrm{C}$. The crystalline diameter calculated by using Scherrer's equation (16) with the value of FWHM increased by annealing and are larger than $50 \mathrm{~nm}$, which is the upper limit of the present arrangement, for the films treated above $350^{\circ} \mathrm{C}$.

The reflection spectra of the above-mentioned samples are shown in Fig. 3 . The reflectance was almost constant for the as-grown films but changed around 820-860 nm for the annealed films. The bandgap energy determined from the spectra is ca. $1.45 \mathrm{eV}$ which is in good agreement with the value reported for CdTe single crystals (3).

Although the as-grown film was p-type, the semiconductivity of the annealed films differed depending upon the annealing temperature. The films treated below $350^{\circ} \mathrm{C}$ were p-type and those treated above $350^{\circ} \mathrm{C}$ were n-type. The semiconductivity of films treated around $350^{\circ} \mathrm{C}$ were difficult to determine by the method employed here.

Effect of the annealing time was also examined. Figure 4 shows the photocurrent-potential relations of the electrochemically deposited p-CdTe films annealed at $350^{\circ} \mathrm{C}$ for $0-12 \mathrm{~h}$. The cathodic photocurrent increased with the increase of annealing time up to $4 \mathrm{~h}$ and then decreased. The anodic photocurrent was observed at the films treated for longer than $7 \mathrm{~h}$.

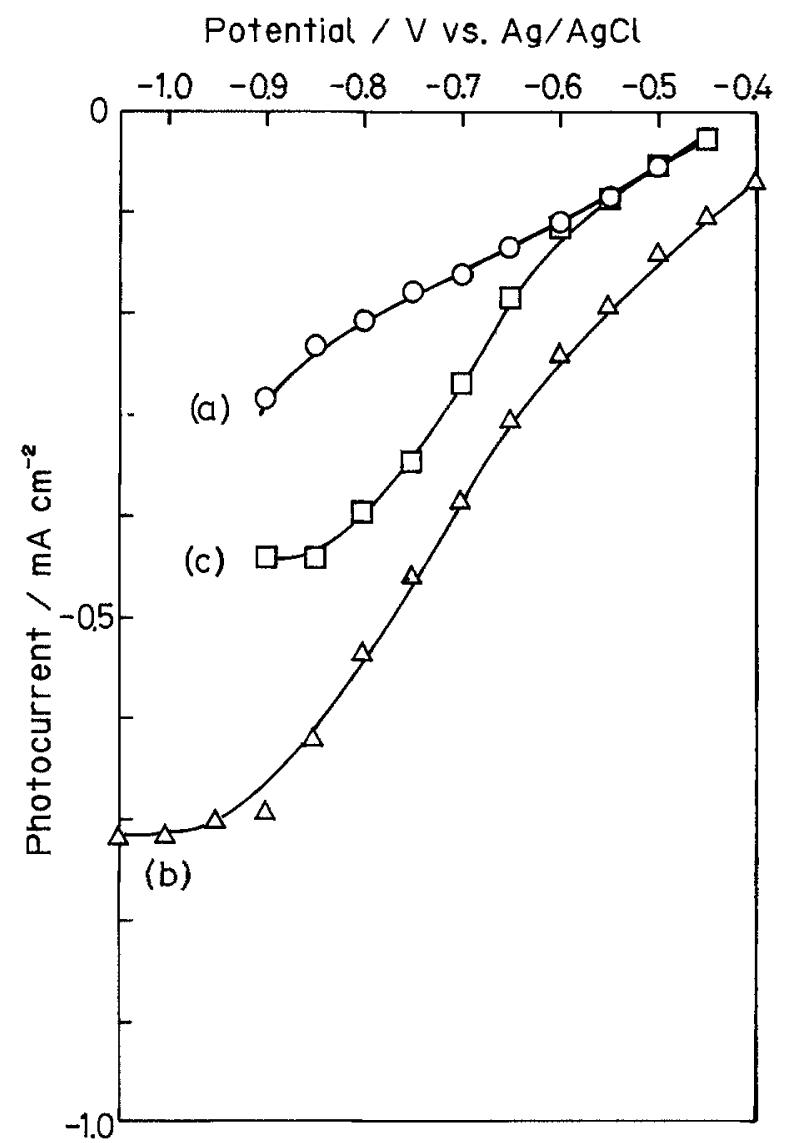

Fig. 6. Photocurrent-potential relations of p-CdTe films. Experimental conditions for the deposition and the photoelectrochemical measurements were the same os those in Fig. 1. (a) Annealed in a He atmosphere ot $350^{\circ} \mathrm{C}$ for $4 \mathrm{~h}$ (somple 2 of Table $\mathrm{I}$ ), (b) modified with $\mathrm{Pt}$ by codeposition then annealed in a $\mathrm{He}$ atmosphere of $350^{\circ} \mathrm{C}$ for $4 \mathrm{~h}$ (sample 4 of Table I), and (c) annealed in a He atmosphere at $350^{\circ} \mathrm{C}$ for $4 \mathrm{~h}$ then modified with Pt by vacuum deposition (sample 7 of Table 1).

The x-ray diffraction patterns of the films used for the measurements presented in Fig. 4 are shown in Fig. 5. The diffraction peaks due to CdTe faces became stronger and sharper by the longer treatment. The diffraction peak due to free $T$ e disappeared after $2 \mathrm{~h}$ treatment.

The films remained as p-type up to $6 \mathrm{~h}$ treatment. The semiconductivity of the films treated for $7 \mathrm{~h}$ was hard to be determined and that of those treated for longer than $8 \mathrm{~h}$ was $n$-type. As already reported, if the films were treated at $200^{\circ} \mathrm{C}$, the films remained p-type with the $\mathrm{x}$-ray diffraction peak due to free Te even after $12 \mathrm{~h}$ treatment (14).

$\mathrm{Pt}$ modification.-The effect of $\mathrm{Pt}$ modification was investigated as listed in Table I. The photocurrent was always increased by $\mathrm{Pt}$ modification either by codeposition or by vacuum deposition, although it was small at the films without annealing (sample 3 and 6). Figure 6 shows the photocurrent-potential relations of sample 4 and 7 as well as that of the annealed film without $\mathrm{Pt}$ modification (sample 2).

Table I. Effect of Pt modification on the photocurrents at the CdTe films

\begin{tabular}{cllr}
\hline Sample & Pt modification & Annealing* & $\begin{array}{c}\text { Photocurrent** } \\
\text { at }-0.8 V / \mathrm{mA}^{*} \cdot \mathrm{cm}^{-2}\end{array}$ \\
\hline 1 & - & - (as-grown) & -0.01 \\
2 & Codeposition & Annealing only & -0.20 \\
3 & Codeposition & After Pt modification & -0.07 \\
4 & Electrodeposition & Before Pt modification & -0.55 \\
6 & Vacuum deposition & Before Pt modification & -0.28 \\
7 & Vacuum deposition & After Pt modification & -0.06 \\
8 & Vacuum deposition & -0.40 & -0.43
\end{tabular}




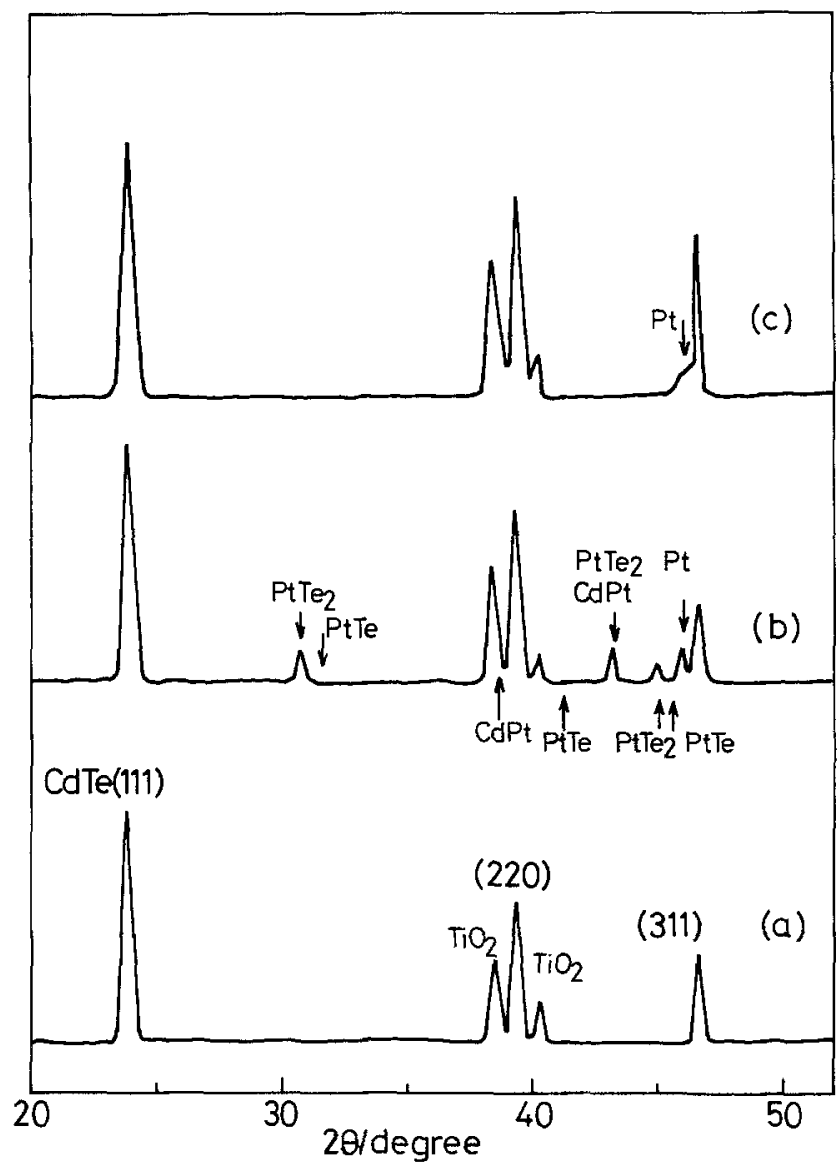

Fig. 7. X-ray diffraction patterns of the $\mathrm{CdTe}$ films used for the experiments presented in Fig. 6. (a) Annealing only (somple 2), (b) Pt codeposition followed by annealing, and (c) annealing followed by $\mathrm{Pt}$ vacuum deposition. Peaks corresponding to $\mathrm{TiO}_{2}$ which existed on substrate (Ti) were also observed. In Fig. 2 and Fig. 5 , no peaks due to $\mathrm{TiO}_{2}$ can be seen because $\mathrm{TiO}_{2}$ portion was covered with epoxy resin when $x$-ray diffraction patterns were obtained.

X-ray diffraction patterns of the films used for the measurements shown in Fig. 6 are shown in Fig. 7. In addition

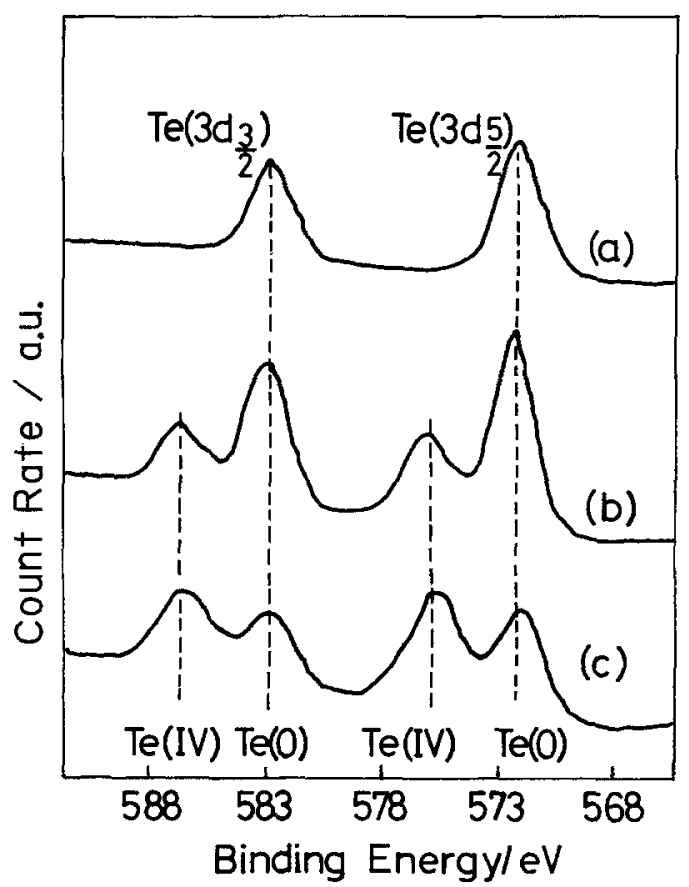

Fig. 8. XPS spectra of p-CdTe films in the region of Te $3 d_{5 / 2}$ and $3 d_{3 / 2}$ peaks. The deposition conditions of the films were the same as those in Fig. 1. The films were annealed in a $\mathrm{He}$ atmosphere at $300^{\circ} \mathrm{C}$ for 4 th then exposed to air for (a) $15 \mathrm{~min}$, (b) 10 days, and (c) 80 days.

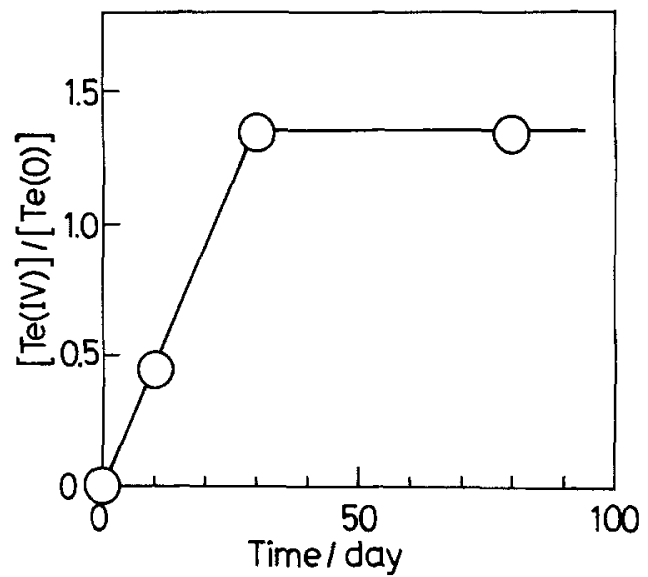

Fig. 9. The ratio of XPS peaks corresponding to $\mathrm{Te}(\mathrm{IV})$ and $\mathrm{Te}(0)$ as a function of air-exposed time.

to $\mathrm{CdTe}$ peaks $\left(2 \theta=23.8^{\circ}, 39.3^{\circ}\right.$, and $\left.46.4^{\circ}\right)(17)$, additional peaks at $2 \theta=46.2^{\circ}$ and $81.3^{\circ}$ corresponding to $\mathrm{Pt}$ (17) were observed with sample 7 (Fig. $7 \mathrm{c}$ ). ${ }^{2}$ Similar patterns were observed with sample 6 . If the annealing was carried out after the $\mathrm{Pt}$ modifications, $\mathrm{Pt}$ reacted with $\mathrm{CdTe}$ and several Pt alloys were formed. Figure $7 \mathrm{~b}$ shows the $\mathrm{x}$-ray diffraction patterns of sample 4 and the diffraction peaks due to PtTe $\left(2 \theta=31.6^{\circ}, 41.2^{\circ}\right.$, and $\left.45.8^{\circ}\right)(17), \mathrm{PtTe}_{2}(2 \theta=$ $30.7^{\circ}, 43.5^{\circ}$, and $\left.45.1^{\circ}\right)(17)$, and $\operatorname{CdPt}\left(2 \theta=38.6^{\circ}, 43.5^{\circ}\right.$, and $76.1^{\circ}$ ) (17) were also observed. ${ }^{3}$ Similar patterns were observed at sample 8 .

XPS spectra of sample 4 and 7 show that platinum existed as metallic $(\mathrm{Pt}(0)){ }^{4}$

The photocurrent-potential relations were not much affected at the thickness of Pt between 5 and $300 \AA$.

Growth of surface oxide layer and its effect on the photoelectrochemical behavior.-It has been reported by Werthen et al. that surface oxide layer grows on CdTe single crystal (18). XPS spectra of the CdTe films which were annealed at $300^{\circ} \mathrm{C}$ in a He atmosphere for $4 \mathrm{~h}$, then

${ }^{2}$ Figure 7 shows only diffraction peaks between $2 \theta=17^{\circ}$ and $2 \theta=52^{\circ}$.

${ }^{3}$ Some of the peaks were very weak and are not obvious in Fig. 7.

${ }^{4}$ Peaks corresponding to $\mathrm{Pt}\left(4 \mathrm{f}_{5 / 2}\right)$ and $\mathrm{Pt}\left(4 \mathrm{f}_{7 / 2}\right)$ appeared only at $75.0 \mathrm{eV}$ and $71.5 \mathrm{eV}$, respectively, which are known to be due to $\mathrm{Pt}(0)$.

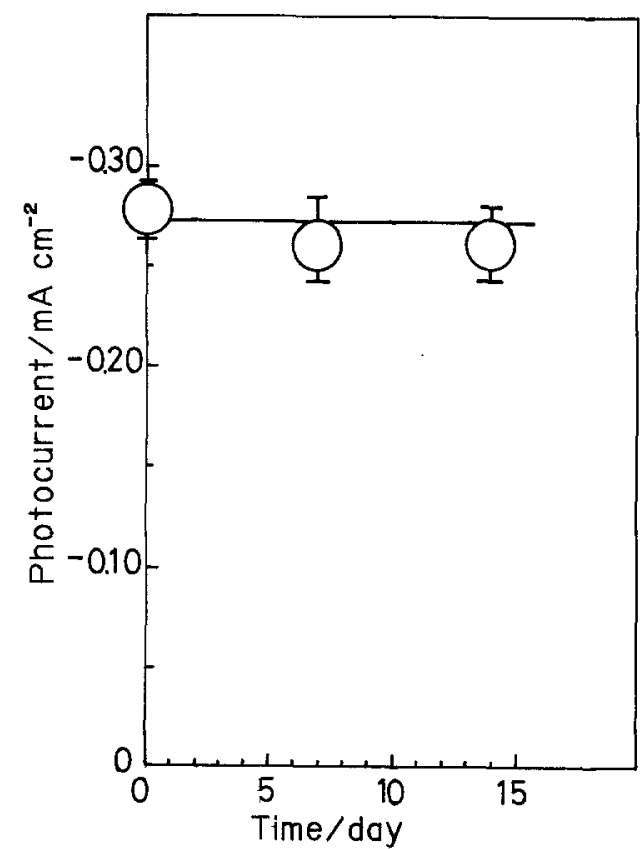

Fig. 10. The photocurrent under illumination of $500 \mathrm{~W} \mathrm{Xe}$ lamp at $-0.70 \mathrm{~V}$ (vs. $\mathrm{Ag} / \mathrm{AgCl}$ ) in $1 \mathrm{M} \mathrm{NaOH}$ at the $\mathrm{CdTe}$ films os a function of air-exposed time. The films were deposited and annealed in the way shown in Fig. 8. 


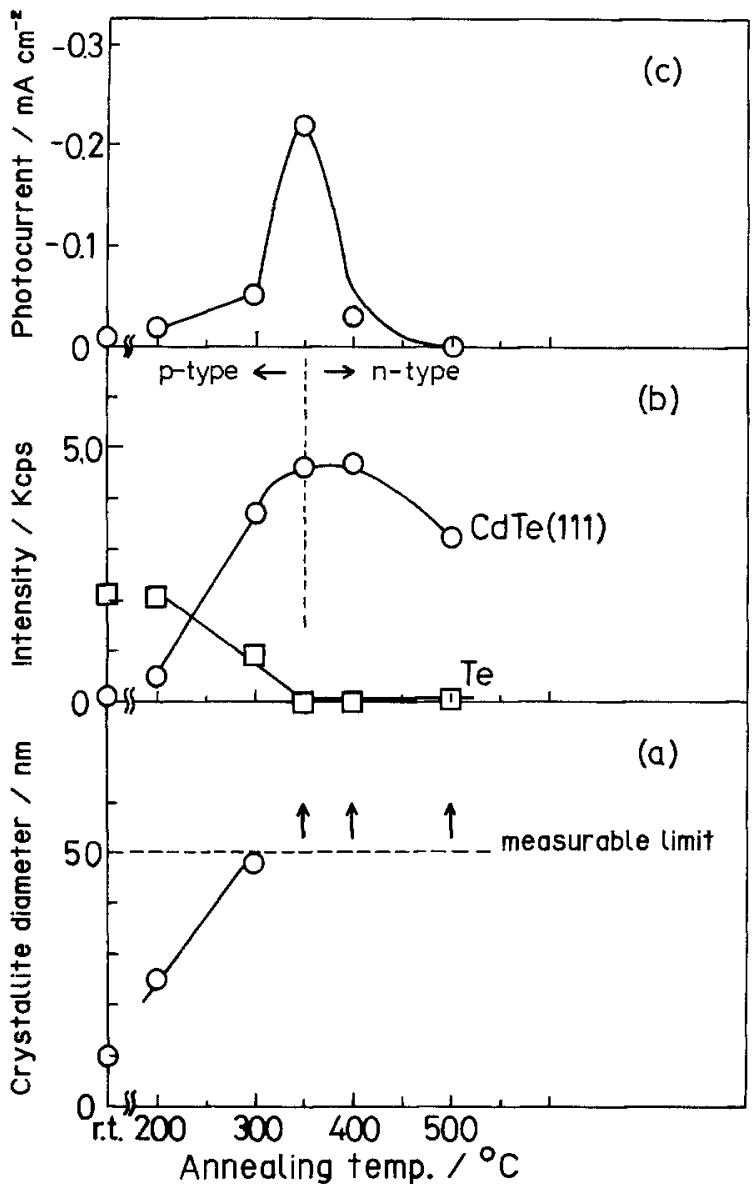

Fig. 11. (a) The crystalline diameter as a function of annealing temperature, (b) the intensity of $x$-ray diffraction peaks corresponding to $\mathrm{CdTe}(111)$ face $(O)$ and free $\mathrm{Te}(\square)$, and (c) the photocurrent at $-0.80 \mathrm{~V}$ (vs. $\mathrm{Ag} / \mathrm{AgCl}$ ). The experimental conditions for the deposition and the photoelectrochemical measurements were the same as those in Fig. 1. The films were annealed in a He otmosphere for $4 \mathrm{~h}$ at the temperature shown as abscissa. The upper limit of the crystallite diameter to be determined in the present experimental arrangement is $50 \mathrm{~nm}$.

exposed to air for $15 \mathrm{~min}, 10$ days, and 80 days are shown in Fig. 8 in the region of Te $3 d_{5 / 2}$ and $3 d_{3 / 2}$ peaks. The peaks at 572.5 and $583.0 \mathrm{eV}$ correspond to $\mathrm{Te}(0)$ and those at 576.0 and $586.5 \mathrm{eV}$ correspond to $\mathrm{Te}(\mathrm{IV})(18,19) .{ }^{5}$ While only peaks due to $\mathrm{Te}(0)$ were observed at the films exposed to air for $15 \mathrm{~min}$, peaks due to Te(IV) were also observed at the films exposed to air for longer time periods. The ratio of $\mathrm{Te}(\mathrm{IV}) / \mathrm{Te}(0)$ increased at the beginning with the increase of the time of exposure to air and reached a constant value as shown in Fig. 9. The shape and the intensity of the peaks which correspond to $\mathrm{Cd} 3 \mathrm{~d}_{5 / 2}$ and $3 \mathrm{~d}_{3 / 2}$ were not affected by the air exposure. These results suggest the formation of $\mathrm{TeO}_{2}$ near the surface by air exposure as proposed by Werthen et al. (18). Air-exposure time did not affect the cathodic photocurrent as shown in Fig. 10. XPS spectra taken after the films were immersed in $1 \mathrm{M} \mathrm{NaOH}$ showed no peaks due to Te(IV), suggesting that the surface oxide dissolved in the solution.

\section{Discussion}

As mentioned before, the major reasons for low efficiencies at as-grown films are the bulk recombination at grain boundaries, the surface recombination due to the existence of excess free Te metal, and the slow hydrogen evolution reaction. The annealing treatments were carried out primarily to increase the crystalline diameter so that the number of grain boundaries should be decreased.

${ }^{5}$ Although White et al. showed the existence of $\mathrm{Te}^{2-}$ in $\mathrm{CdTe}$ (19), Werthen et al. suggested that Te existed as Te(0) in CdTe In our measurements, the position of Te peaks of sputtered CdTe films agreed with that of Te peaks of sputtered elemental Te within experimental error, suggesting that Te existed as $\mathrm{Te}(0)$ in CdTe.

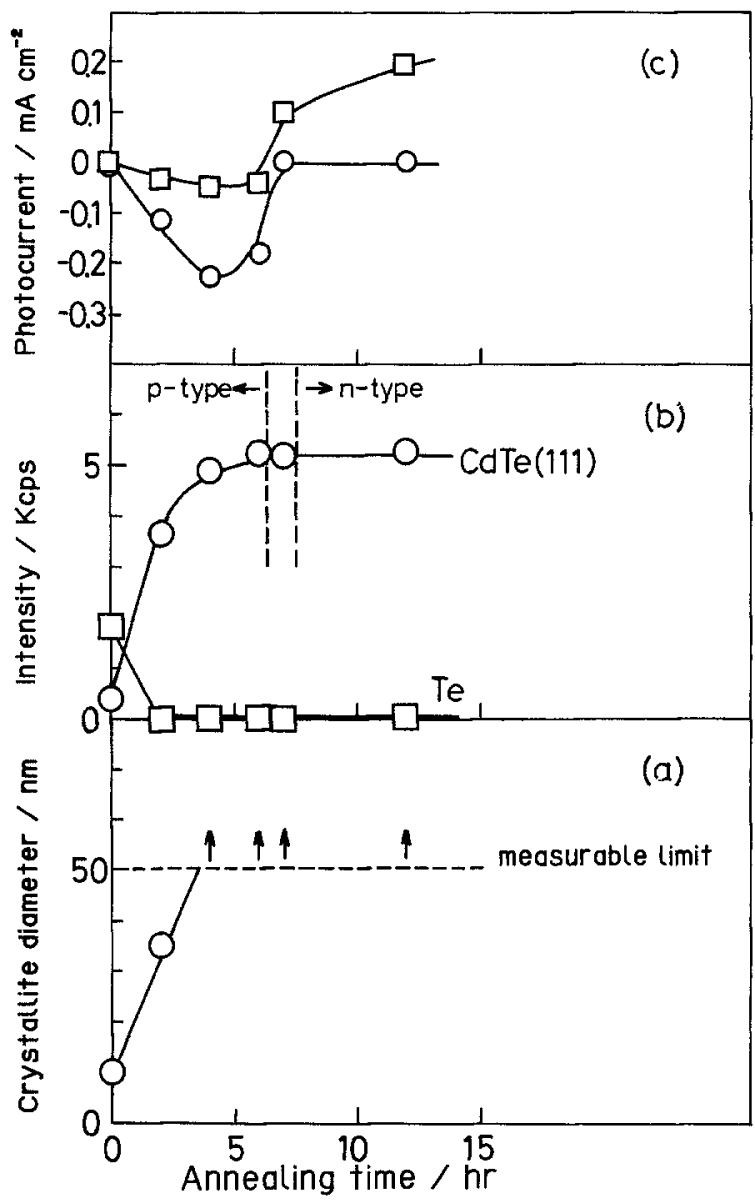

Fig. 12. (a) The crystallite diameter as a function of annealing time, (b) the intensity of $\mathrm{x}$-ray diffraction peaks corresponding to $\mathrm{CdTe}$ (III) face $(O)$ and free $\mathrm{Te}(\square)$, and $(c)$ the photocurrents at $-0.80 \mathrm{~V}(O)$ and at $-0.50 \mathrm{~V}(\square)$. The experimental conditions for the deposition and the photoelectrochemical measurements were the same as those in Fig. 1. The films were annealed in a $\mathrm{He}$ atmosphere at $350^{\circ} \mathrm{C}$ for a period shown in abscissa.

Crystalline diameter, intensity of $\mathrm{x}$-ray diffraction peaks, and photocurrents are plotted as a function of the annealing temperature (Fig. 11) and of the annealing time (Fig. 12 at $350^{\circ} \mathrm{C}$ and Fig. 13 at $200^{\circ} \mathrm{C}$ ). As shown in Fig. 13 the annealing at $200^{\circ} \mathrm{C}$ increased the crystalline diameter but did not affect the free Te concentration. In this case the increase of the photocurrent is solely due to the increase of crystalline diameter. The annealing above $300^{\circ} \mathrm{C}$ not only increased the crystalline diameter but also removed the free Te which existed near the surface and acted as the surface recombination center. Thus, the annealing improved the efficiency due to these two effects. The cathodic photocurrent, however, declined by the annealing at too high temperature or for too long time (Fig. 11, 12). The films were converted to n-type by these treatments and even anodic photocurrents were observed (Fig. 12). This is due to the removal of the lattice Te from $\mathrm{CdTe}$ crystal. The Te vacancy is known as a donor center (20). Although the details of the effect of the annealing on the composition and the electronic properties of the films will be reported elsewhere (21), it should be emphasized here that the effect of the annealing on the photocurrent is the result of the increase of the crystalline diameter, the decrease of free $\mathrm{Te}$ concentration and the change of the electronic properties.

$\mathrm{Pt}$ modification was carried out with the hope that the hydrogen evolution reaction is enhanced by $\mathrm{Pt}$ which is known as a good catalyst for this reaction (22). The results shown in Table I, Fig. 6, and Fig. 7 support that this expectation was correct. However, the increment by the treatment is not as large as those reported for p-type single-crystal electrodes, e.g., p-InP (23), and the photocurrent at RHE is still small. Thus, it can be concluded 


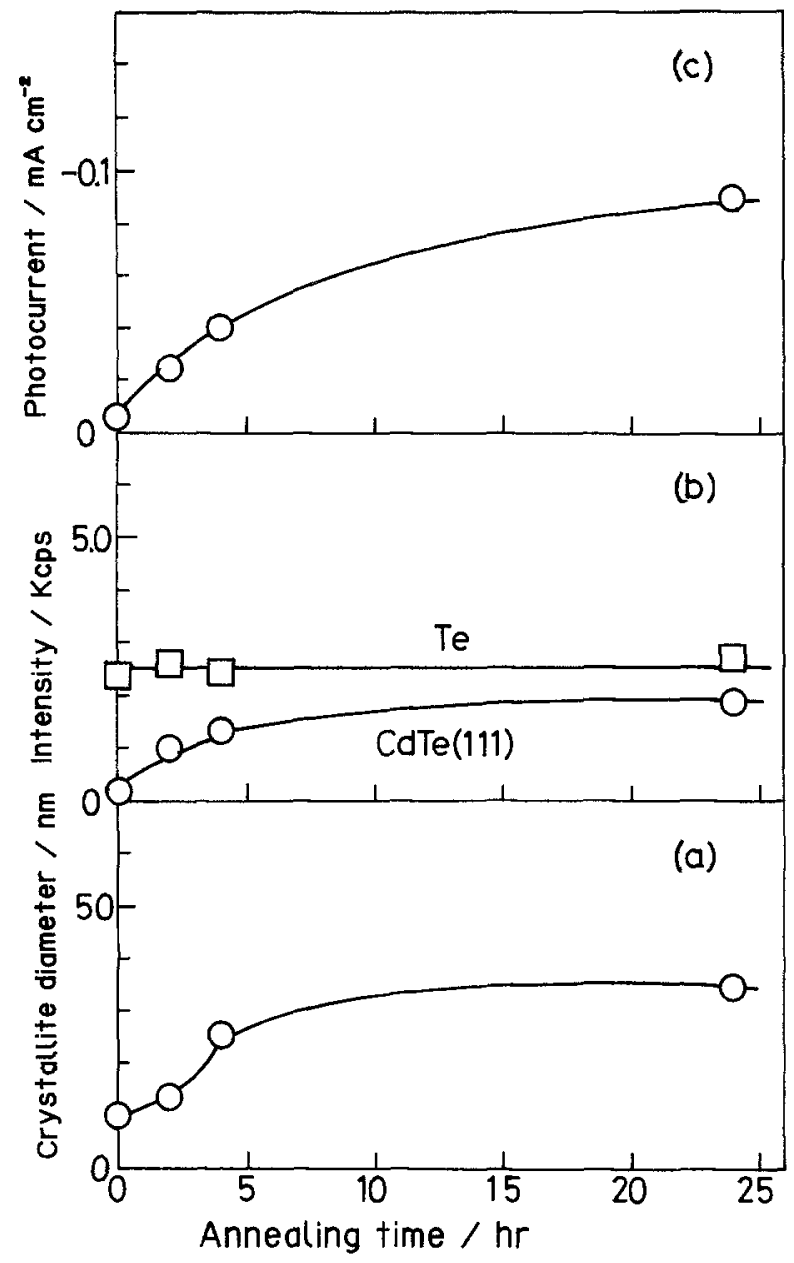

Fig. 13. (a) The crystallite diameter as a function of annealing time, (b) the intensity of $x$-ray diffraction peaks corresponding to $\mathrm{CdTe}$ (111) tace $(O)$ and free $\mathrm{Te}(\square)$, and $(\mathrm{c})$ the photocurrent at $-0.80 \mathrm{~V}$. The films were annealed at $200^{\circ} \mathrm{C}$. Other conditions were as same as those in Fig. 12.

that the bulk recombination is still the major reason for the low efficiency at these films. The role of $\mathrm{Pt}$ alloys found in the films annealed after the Pt modification is not clear.

According to Heller, surface oxide layer plays an important role in determining the efficiency for photoelectrochemical hydrogen evolution reaction at $\mathrm{p}$-InP (15). In the present case, however, although the surface is very easily oxidized by exposing it to air, the oxide layer thus formed disappears just by immersing the film into $1 M \mathrm{NaOH}$, and, therefore, cannot play any role in the photoelectrochemical properties of CdTe films. This result agrees with the fact that there is no $p \mathrm{H}$ dependence of the flatband potential (24), which also suggests no oxide layer at the surface in contact with solution.

\section{Acknowledgments}

Thanks are due to Professor T. Yokokawa and Dr. T. Maekawa and to Professor Y. Matsunaga for the help in the $x$-ray diffraction measurements and reflection spectra measurements, respectively. Vacuum deposition was carried out with the help of Dr. M. Taniwaki for which we are most grateful. Mr. Kiya is acknowledged for con- structing electrochemical cells. This work was partially supported by a Grant-in-Aid for Scientific Research, Ministry of Education, Science and Culture.

Manuscript submitted April 2, 1985; revised manuscript received July $9,1985$.

Hokkaido University assisted in meeting the publication costs of this article.

\section{REFERENCES}

1. (a) A. Fujishima and K. Honda, Nature, 238, 37 (1972); (b) A. Heller, Acc. Chem.Res., 14, 154 (1981); (c) A. J. Bard, J. Phys. Chem., 86, 172 (1982).

2. (a) B. Miller and A. Heller, Nature, 262, 680 (1976); (b) W. J. Danaher and L. E. Lyons, ibid., 271, 139 (1978); (c) J. F. McCann and M. Skyllas Kazacos, J. Electroanal. Chem., 119, 409 (1981).

3. K. W. Böer and A. Rothwarf, Ann.Rev.Mater. Sci., 6, 303 (1976).

4. S. Wagner, in "Solid State Chemistry and Energy Conversion and Storage," J. B. Goodenough and M. S. Whittingham, Editors, p. 109 Adv. in Chem. Ser. of ACS, No. 163 (1977).

5. B. M. Basol and O. M. Stafsudd, Thin Solid Films, 78, 217 (1981).

6. S. S. Chern, H. R. Vydyanath, and F. A. Kröger, J. Solid State Chem., 14, 33 (1975).

7. J. G. Werthen, J-P. Häring, A. L. Fahrenbruch, and R. H Bube, J. Appl. Phys., 54, 5982 (1983).

8. A. B. Ellis, S. W. Kaiser, J. M. Bolts, and M. S. Wrighton, J. Am. Chem. Soc., 99, 2839 (1977).

9. J. O'M. Bockris and K. Uosaki, This Journal, 124, 1348 (1977).

10. (a) L-S. R. Yeh, P. G. Hudson, and A. Damjanovic, J. Appl. Electrochem., 12, 153 (1982); (b) D. K. Roe, L. Wenzhao, and $\mathbf{H}$. Gerischer, J. Electroanal. Chem. 136, 323 (1982); (c) I. Markov and M. Ilieve, Thin Solid Films, 74, 109 (1980); (d) M. Cocivera, A. Darkowski, and B. Love, This Journal, 131, 2514 (1984); (e) M. P.R. Panicker, M. Knaster, and F. A. Kröger, ibid., 125, 566 (1978).

11. (a) J. H. Reeves and M. Cocivera, This Journal, 131, 2042 (1984); (b) G. J. Houston, J. F. McCann, and D. Haneman, J. Electroanal. Chem., 134, 37 (1982); (c) G. Hodes, J. Manassen, and D. Cahen, Nature, 261, 403 (1976); (d) M. Skyllas Kazacos and B. Miller, This Journal, 127, 869 (1980); (e) M. Tomkiewicz, I. Ling, and W. S. Parsons, ibid., 129, 2016 (1982).

12. K. Uosaki, M. Takahashi, and H. Kita, Electrochim. Acta, 29, 279 (1984).

13. M. Takahashi, K. Uosaki, and H. Kita, J. Appl.Phys., 55, 3879 (1984)

14. M. Takahashi, K. Uosaki, and H. Kita, This Journal, 131, 2304 (1984)

15. A. Heller, J. Vac. Sci. Technol., 21, 559 (1982).

16. J. R. Anderson, "Structure of Metallic Catalysts," p. 365, Academic Press, London (1975)

17. ASTM X-Ray Powder Data, 15-770, 19-193, 19-192, 14-7, 18-976, 17-920.

18. J. G. Werthen, J-P. Höring, and R. H. Bube, J. Appl. Phys., 54, 1159 (1983).

19. H. S. White, A. J. Ricco, and M. S. Wrighton, J. Phys. Chem., 87, 5140 (1983).

20. D. de Nobel, Philips Res. Rep., 14, 361 (1959).

21. M. Takahashi, K. Uosaki, and H. Kita, J.Appl.Phys., 58, 4292 (1985).

22. J. F. Llopis and F. Colom, in "Encyclopedia of Electrochemistry of the Elements," Chap. VI-4, A. J. Bard, Editor, Marcel Dekker, Inc., New York and Basel (1976).

23. W. D. Johnston, Jr., H. J. Leamy, B. A. Parkinson, A. Heller, and B. Miller, This Journal, 127, 90 (1980).

24. J. L. Sculfort, R. Triboulet, and P. Lemasson, ibid., 131, 209 (1984) 